\title{
Racers' attractive looks, popularity, and performance: how do speedboat racers react to fans' expectations?
}

\section{Eiji Yamamura ${ }^{1} \cdot$ Ryohei Hayashi $^{2} \cdot$ Yoshiro Tsutsui $^{3} \cdot$ Fumio Ohtake $^{4}$}

Received: 13 September 2019 / Revised: 13 October 2020 / Accepted: 27 October 2020 /

Published online: 17 November 2020

(c) Japanese Economic Association 2020

\begin{abstract}
Using a large sample of individual-level records in Japan speedboat racing where men and women racers participate, we investigated how racers' performance meets fans' pre-race expectations. To control for endogeneity bias, we measured the order of racers' attractiveness randomly determined in each race and then used this order as instrument for measuring racers' popularity. The fixed-effects IV estimations revealed the following. (1) Racers who are more attractive than their competitors tend to be more popular even after controlling for the condition of the race, racer ability, and other characteristics. (2) More popular men show better performance in the race even if the reward does not vary according to popularity; such tendency is not observed for women. This study contributes a novel setting for determining the expectation-enhancing effects of physical attractiveness.
\end{abstract}

Keywords Beauty $\cdot$ Race betting odds $\cdot$ Popularity $\cdot$ Performance $\cdot$ Gender difference $\cdot$ Tournaments

\section{Introduction}

Are players motivated by others' expectations? In the framework of standard economics, the answer depends on whether a player's net benefit increases when the outcome meets others' expectations. That is, a player is motivated if his or her benefits from meeting expectations exceed his or her cost. In other words, a player is not motivated if the benefit is the same regardless of others' expectations.

Eiji Yamamura

yamaei@seinan-gu.ac.jp

1 Department of Economics, Seinan Gakuin University, 6-2-92 Sawaraku Nishijin, Fukuoka 814-8511, Japan

2 Faculty of Social Relations, Kyoto Bunkyo University, Kyoto, Japan

3 School of Economics and Management, Kochi University of Technology, Kochi, Japan

4 Department of Economics, Osaka University, Osaka, Japan 
Meanwhile, in reality, a player is likely to increase his or her motivation to win when cheers of encouragement are heard from spectators. If so, that support could improve the performance of players. However, economic researchers have yet to examine this notion. Hence, this paper aims to explore whether encouragement from spectators improves player performance using novel data under the quasiexperimental setting of speedboat races.

Players of professional sports possibly become popular not only through their performance but also through their appearance. More physically attractive players are thought to be more popular than other players, even when performance is equal. Accordingly, good-looking players bear on their shoulders the expectations of others. The present study aimed to examine the effect of varying relative attractiveness on individual performance by considering the incentives to meet others' expectations. Further, we compared the effects of men's attractiveness with those of women's. This work is the first to analyse bettors' expectations based on the perceived effects of facial attractiveness on performance and the related gender difference. Japan speedboat races provide a setting for a natural experiment for comparing men's behaviour with women's under the same condition (Booth and Yamamura 2018). We intended to analyse unique performance data of speedboat races, in which men and women racers compete in a highly competitive environment. Our data were in panel form; we gathered information on each racer's place in races and recorded time across all races in which they competed. We analysed a total of over 35,000 women race observations and over 400,000 men race observations during the period 2015-2017. Professional speedboat racers in Japan number approximately 1600 , including both women and men. Each race had different competitors. Using the racers' photographs that were officially open to the public, we measured the attractiveness and the order of such attractiveness among six racers participating in a race. In this way, this study determined the relative attractiveness effect, which varies according to the situation. Then, we analysed how the relative attractiveness influences the racers' performance and compared the case between men and women racers. In the boat race, the rewards depend on the grade of the race and one's place in the race, but do not differ according to popularity among fans. Thus, we could investigate how individual racers have an incentive to meet the expectations of others, dictated by racers' relative physical attractiveness, even when economic return and racers' skills are controlled.

Our empirical strategy was as follows: we assumed that racers' physical attractiveness can influence popularity among bettors', but not the racers' performance in the race. Hence, attractiveness was used as an excluded instrumental variable (IV) to control for the endogeneity bias of popularity in the estimation of the effect of racers' popularity on performance. The strategy revealed the following. (1) In the first stage of IV estimation, racers who were more attractive than other competitors tended to be more popular, as reflected in betting odds, even after controlling for various variables that captured racer's ability. (2) In the second stage of IV estimation, the more popular racers recorded better race times. (3) More popular men finished with a higher place in races, even though popularity had nothing to do with their gains. Meanwhile, such tendency was not observed for women. 
The third finding above is of particular interest. Men have a great incentive to improve their performance in response to expectation from fans even though the return is constant, whereas women do not have such an incentive.

The remainder of the paper is constructed as follows. Section 2 briefly reviews related literature and describes the setting of speedboat racing in Japan. Section 3 presents the construction of data. Section 4 provides the analytical framework of our hypotheses and explains the estimation model. Section 5 gives the estimation results and our interpretation of the major findings. Section 6 provides our conclusions and implications for future research.

\section{Related literature and the setting}

\subsection{Related literature}

The expected return, such as earnings, from performance leads individuals to make an effort to improve their skill, accumulating human capital. Other factors influence earnings. The seminal work of Hamermesh and Biddle (1994) provided evidence that the degree of an individual's attractiveness is positively related to their earnings. Various other researchers have subsequently analysed the influence of beauty in the labour market (Doorley and Sierminska 2015; Fletcher 2009; Parrett 2015; Price 2008). ${ }^{1}$ Physical attractiveness derives sizable rents, considered as a beauty premium reflected in the level of earnings in the labour market (Hamermesh and Biddle 1994). This effect of beauty can be attributed to two reasons (Biddle and Hamermesh 1998). The first is that employers simply prefer to employ attractivelooking applicants for $\mathrm{s}$ job. ${ }^{2}$ The second is the production-enhancing effect, which states that physical attractiveness directly increases productivity. For instance, attractive-looking attorneys more easily obtain social skills, which are effective for convincing judges and juries. Physically attractive workers possibly have better communication skills, which increase their wage through interaction with employers (Mobius and Rosenblat 2006). In the case of professional sports, the more physically attractive players who play well are more likely to have opportunities for additional earnings through side jobs. That is, beauty premiums given to attractive individuals depend on their work performance. Consequently, more attractive players make greater effort to improve their performance, which is called the effort-enhancing effect of beauty (Ahn and Lee 2014).

\footnotetext{
1 The roles and impact of beauty in various real-world settings have been examined, such as happiness (Hamermesh \& Abrevaya 2013), charitable giving (Jenq et al. 2015), fund raising (Price 2008), chess (Dreber et al. 2013), and political election (Berggren et al. 2010; 2017; King and Leigh 2009). Experimental methods have been applied to consider the influence of beauty (Andreoni and Petrie 2008; Eckel and Petrie 2011; Mobius and Rosenblat 2006).

${ }^{2}$ Discrimination effects are observed in various settings. Teachers tend to devote more attention to better-looking students (Hatfield and Spencer 1986). Charitable giving increases with the physical attractiveness of female solicitors involved (Craig et al. 2006).
} 
The case of professional sports players merits consideration because it enables scrutiny of the effect of players' physical attractiveness after controlling for their performance. More attractive-looking American football players are paid greater salaries, and this premium persists even when controlling for player performance (Berri et al. 2011). In team sports, individual attractiveness influences team performance, a phenomenon reported in the office setting: a worker's attractiveness is related to the firm's performance (Pfann et al. 2000). Meanwhile, an individual's beauty effects can be considered to depend on the team's, and cannot be analysed individually. In individual sports, communication skills are proven ineffective at improving performance. Ahn and Lee (2014) pointed out that players with better looks can gain wider publicity, which in turn can lead to opportunities for additional earnings. They hypothesized that this effect of attractive looks increases as these players improve their performance; attractive players thus have strong incentive to improve their performance. They showed that the performance of more attractive women golfers tended to be better than those who scored lower in attractiveness. In other words, the physical attractiveness of women players boosts their popularity, which directly increases the incentive for better performance. They further argued that beauty premiums may not be entirely rents. However, their argument cannot be generalized because no study has examined whether the mechanism holds for male players.

A number of studies have shown the differences in behaviour between men and women under the same situation.Gneezy et al. (2003) provided evidence that women are less likely to show their real ability in more competitive environments compared with men, even if their performance is similar in non-competitive environments. ${ }^{3}$ Using data on tennis players, Paserman (2010) found the clear difference in performance between men and women tennis players under great competitive pressure in a setting with large monetary rewards. Compared with women players, attractive men players are more able to improve their performance when additional earnings from a side work are large. Similarly, in speedboat races, men racers are more likely to adopt aggressive strategy compared with women, leading to improvement in men's performance (Booth and Yamamura 2018).

Studies have analysed the effects of absolute physical attractiveness. However, the influence of attractiveness depends on the situation. The most beautiful girl in a high school that becomes a fashion model or an actress becomes average in terms of looks in her new world. That is, the degree of beauty is determined relatively, rather than absolutely. Physical attractiveness leads people to obtain better social skills. It has also been shown to foster workers' confidence, leading to increased wage levels (Mobius and Rosenblat 2006). Social skills and confidence are formed during a long period of time, and so do not vary depending on the situation. Therefore, these effects are fixed in the short period. An individual's relative attractiveness and

\footnotetext{
3 Studies have investigated how performance differs according to gender in competitive environments (e.g. Booth 2009; Cárdenas et al. 2012; Dreber et al. 2011; Gneezy and Rustichini 2004; Gneezy et al. 2009; Niederle and Vesterlund, 2007; 2011). Researchers have also analysed the gender difference of attitudes towards risk (e.g. Booth et al. 2014; Dreber et al. 2014; Khachatryan et al. 2015).
} 
its effects frequently change if his/her objects of comparison change. Research has deconstructed the effect into the fixed effect and the varying one.

\subsection{Overview of speedboat racing in Japan}

Himura (2015) is our principal source of information in this section. In speedboat racing in Japan, men and women racers receive exactly the same intensive training for 1 year in only one training school, the Yamato Boat School. Both men and women train under the same condition and must pass the final examination to be qualified as a professional speedboat racer. After becoming racers, they compete in races under the same rules and conditions.

At present, Japan has 1600 racers, composed of 1400 men and 200 women. There are 24 speedboat racing stadia mainly located in the western part of Japan. Generally, boat races are randomly held about 4 days per week in each stadium; 1 day sees 12 races. Six racers compete in a race and are generally composed of same-gender racers. Racers participate in races in various stadia. The racing circuit is regulated to be $600 \mathrm{~m}$ in length. A race involves three laps; the total race distance is $1,800 \mathrm{~m}$. Races are classified into five grades. The highest grade is Super Grade (SG), followed by Grade I (GI), Grade II (GII), Grade III (GIII), and 'Usual', which is the lowest grade. Racers can receive rewards according to race finish order, from the winner (first place) to the bottom (sixth place). The reward for the first-place winner of SG races is around USD 300,000. The rewards for the first-place winner in the subsequent race grades are as follows: USD 100,000 (GI), USD 40,000 (GII), USD 10,000 (GIII), and under USD 10,000 (Usual). The rewards in SG races for the other winners are as follows: USD 150,000 (second place), USD 50,000 (third place), USD 20,000 (fourth place), USD 10,000 (fifth place), and under USD 10,000 (sixth place). These rewards decrease as the grades of racers decline. That is, there are wide variations in the reward offered according to race grade and place in the race.

In addition to race grades, racers are also classified into four grades, namely, A1 (top grade), A2, B1, and B2 (bottom grade). Racers' grades are determined by their past performances: a higher winning ratio leads to a higher grade. The Japanese Motorboat Association determines race participants. In most SG and GI grade races, A1 racers are selected to participate. ${ }^{4}$ Inevitably, there is a wide gap in total rewards between A1 racers and other grade racers during a season. In addition, A1 racers are likely to obtain opportunities for additional earnings, such as appearance in TV commercials, even though speedboat racing is not so popular a sport in Japan compared with other professional sports like football or baseball. That is, A1 racers possibly enjoy the 'super star' effect (Rosen 1981). However, apart from SG and GI races, racers of various grades, from A1 to B2, are evenly and randomly assigned to participate in Usual races. Consequently, in Usual races, A1 racers compete with lower-grade racers.

\footnotetext{
${ }^{4}$ The exceptional cases that A2 racers participate in SG and G1 races, but only if their performance is extremely high during the season.
} 
The probability of winning a race varies according to the competitors in the race. That is, the winning probability of an A2 racer is low in a race where the other five competitors are A1 racers. Meanwhile, the winning probability of an A2 racer is higher when the competitors are $\mathrm{A} 2, \mathrm{~B} 1$, and $\mathrm{B} 2$ racers. The competitors in a race change in each race, and, as such, the relative position of a racer's characteristics, such as his/her grade, is different in each race. The same holds true for the degree of a racer's physical attractiveness. A racer who is the most attractive among competitors in one race may be the least attractive in another set of competitors in a different race. Therefore, physical attractiveness changes according to races even though a racer's appearance is fixed. Fans of a specific racer may always bet on the racer regardless of the race, but apart from this case, popularity, which can be captured by betting odds, depends on the competing racers and thus varies across races. Popularity is thought to depend on fans' discrimination based on racers' physical attractiveness. Even if the fixed effect of attractiveness is removed by fixed effect estimation, the relative effect of attractiveness persists because of the relative position of racers' attractiveness in each race.

The characteristics of the boat motors, such as maker and type, are the same in all races. However, a disparity in motor performance has become apparent, attributed to differences in maintenance and deterioration through races. Such differences in motor performance have a significant influence on racers' outcomes in a race. Motor units are randomly assigned to racers by drawing of lots in every race. Meanwhile, a racer's lane on the track is also considered a key factor affecting the probability of the racer's winning. ${ }^{5}$ Generally, racing in an inner lane overwhelmingly confers an advantage. Hence, a racer's performance is determined by not only the racer's ability but other conditions as well. Therefore, low-skilled racers assigned with a better motor unit and the inner lane have a greater chance to win a race, even when competing with higher-skilled and higher-grade racers in a race. Inevitably, the disparity in racers' performance is lessened.

Before the races begin, when the window of time for betting has expired, photos of the faces of racers alongside their recent records are displayed on the electric bulletin board. Hence, bettors can make a decision to place a bet by looking at racers' faces in addition to their statistics. Racers can know the betting odds directly before they start. So, the betting odds possibly influence racer's performance.

\section{Description of data}

\subsection{Race level data}

The study used individual records for theperiod April 2014 to October 2016. The data were collected from the online database officially provided by the Japan

\footnotetext{
5 Generally, the operating commission configured the race programme by taking racers' abilities and compatibility into consideration so that racers could equally compete in the race (Hiruma, 2015). Thus, a racer's lane was considered to be assigned, although the assignment process was not open.
} 
Speed-boat Association. ${ }^{6}$ We obtained racers' performance measured by racers' place in races and race time. We sought detailed information on the characteristics of the races, such as stadia location, natural conditions (weather, wind speed, wave), racers' grades, lane assignments, and performance record of motor units assigned to racers. ${ }^{7}$ The database does not include precise information on racers' weight (capturing the condition of racers on the day of the race) and the grade of races. To obtain these data, we used another source, 'Boat Advisor', a database provided by a private firm. ${ }^{8}$

The data were subsequently integrated into an original panel dataset for racers and the races in which they participated. We used racers' place in races and time record as measures for racers' performance. A total of 24 stadia were included in the study, which cover a wide variety of locations and statuses. For all races held in these 24 boat race stadia, all of the records of racers' places in races are available. However, in 18 stadia, racers' time records are provided only for racers placed in the first, second, third, and fourth places. ${ }^{9}$ Hence, the sample size used for analysing the racers' time is smaller than that for analysing the place in the race. We restricted the performance data of racers to the active list in the first half season of 2017 (from May to November in 2017). We evaluated their photos in May 2017, which were made open to the public in the official website of the Japan Speed-boat Association, for measuring the racers' attractiveness. In a season, 1,300 men and 180 women racers are featured on the website.

During the study period, the average number of races in which each of these racers participated was 350 for men and 200 for women. The sample for estimation comprised all those races with complete information on racers' records. Therefore, in total, the sample size reached 430,000 and 36,000 person-race observations for men and women racers, respectively. One advantage of this study is that the sample size is far larger than the other datasets used to examine the effect of physical attractiveness (Ahn and Lee 2014; Biddle and Hamermesh 1998; Hamermesh and Biddle 1994; Hamermesh and Parke 2005). Our sample size is also far larger than that in existing works that analysed gender differences in work performance (e.g. Dreber et al. 2011; 2014; Paserman 2010).

Table 1 gives the definition of the key variables used for estimations. In most of the variables, the mean values were similar between men and women. The fixed characteristics were controlled in the estimation. Hence, the key variables were the order of variables among six same-gender competitors in a race. That is, the variables associated with order captured the relative position among competitors. Racers'

\footnotetext{
${ }^{6}$ The programme of racers is from https://www1.mbrace.or.jp/od2/B/dindex.html. Race results are from https://www1.mbrace.or.jp/od2/K/dindex.html

7 Places in races where a motor unit is used are converted into points for a motor unit. Further, the points differ according to the race grade. The index of a motor unit's performance is calculated by aggregating the points before the race.

8 See https://boat-advisor.com [in Japanese].

9 Seven stadia (Suminoe, Marugame, Kiryu, Miyajima, Biwako, Karatsu, and Amagasaki) provided both the racers' places in races and time. There was no difference in average characteristics, such as attendance and size of municipality where the stadium is located, between these 6 stadia and the other 18 .
} 


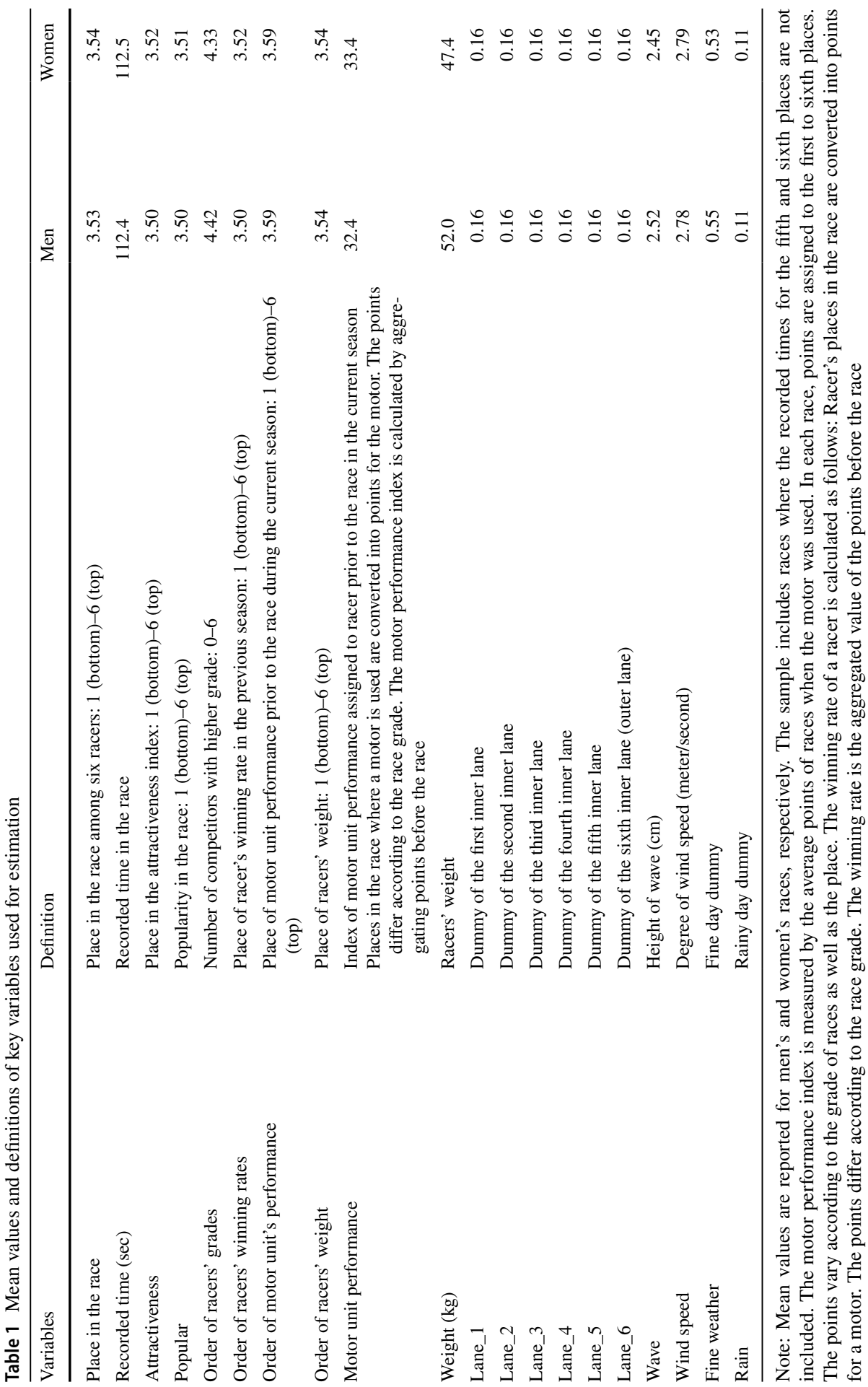




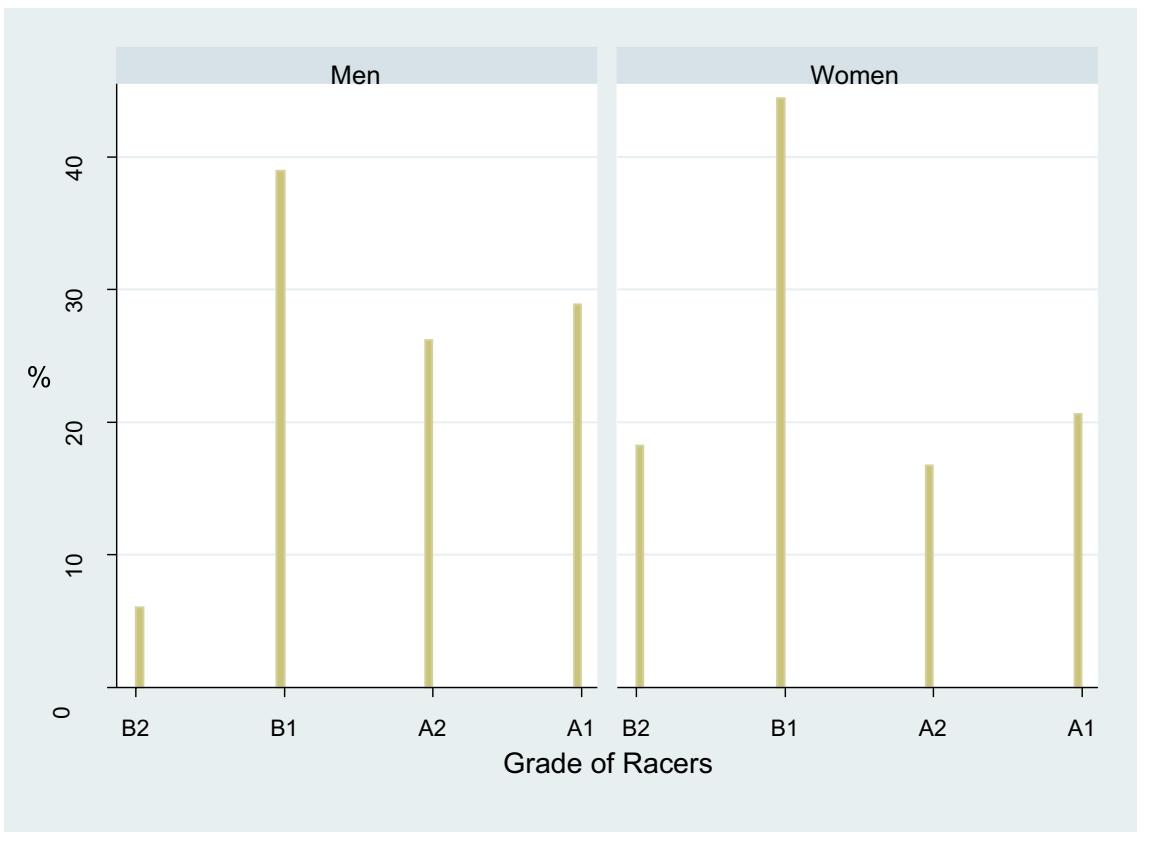

Fig. 1 Distribution of racers' grades

grades were captured by the fixed effects in the estimation because these hardly changed during the studied period.

Figure 1 illustrates the distribution of men and women racers' grades. The percentages of women racers classified as A1 and A2 were remarkably lower compared with men racers. That is, as a whole, the racer grade for women tended to be lower than that of men. Racers in the highest grade, A1, are more likely to gain opportunities for additional earnings because they are possibly greatly supported and preferred by fans. That is, they possibly enjoy the super star effect (Rosen 1981) and so have a greater incentive to improve their performance in races.

\subsection{Measurement of physical attractiveness}

In the evaluation of attractiveness, we referred to existing methods (e.g. Ahn and Lee 2014; Biddle and Hamermesh 1998; Dreber et al. 2013; Mobius and Rosenblat 2006). On May 2017, we measured the attractiveness of racers from their frontal head-and-shoulder photographs wearing the same uniform, which are open to the public on the official website of the Japan Speed-boat Association. ${ }^{10}$ From the site, we gathered the photos of 1296 men racers and 180 women racers. We recruited 55 men and 63 women students from Seinan Gakuin University to evaluate the

\footnotetext{
10 Men's uniforms are in black; women's are in pink (https://www.boatrace.jp/owpc/pc/data/racersearch/ index).
} 
attractiveness of racers by looking at the photos. To collect pure physical attractiveness scores not influenced by player performance, fame, and popularity, we selected evaluators who were not at all familiar with speedboat racing. They were presented with the photos in random order through the originally constructed evaluation system on a computer. The evaluators were asked to rate the physical attractiveness of each racer on a ten-point scale, with 1 indicating 'Not at all attractive' and 10, 'Very attractive'. This rating scale was almost the same as that in Dreber et al. (2013). A total of 118 evaluators rated 1496 photos racers; each photo was rated 118 times. $^{11}$ Different evaluators had different standards for average attractiveness. To remove the influence of individually different standards, we used standardized scores. The standardized attractiveness score for a racer is calculated as follows;

$$
\text { Standardizedscore }_{m i}=\frac{\text { Score }_{m i}-\overline{\text { Score }_{m n}}}{S_{m n}},
$$

where $m$ is the evaluator, $i$ the racer, and $n$ is the total number of racers (1496). $S_{m}$ is the standard deviation of evaluator $m$ 's scores for the 1496 racers. Score $_{m n}$ is the mean value of evaluator $m$ 's scores for the 1496 racers. That is,

$$
\text { Score }_{m}=\frac{\sum_{i}^{n} \text { Score }_{m i}}{n}
$$

Hence, Standardizedscore ${ }_{m i}$ has a negative value if racer $i$ 's attractiveness score evaluated by $m$ is lower than the mean value of the score based on 1496 racers.

Hence, we gathered 118 standardized attractiveness scores for each racer, because there were 118 evaluators, and calculated the scores for the 1496 racers. The mean value of the standardized attractiveness scores was used as racer $i$ 's attractiveness score. The correlation between the men and women students' average scores was 0.75 , indicating high correlation between different groups. Thus, the attractiveness standards were considered similar within the sample.

A racer's attractiveness was then compared with that of the competitors' in a race. Even when the standardized attractiveness scores of "Racer A" were not so high, "Racer A" had the most attractive appearance in a race if the five other racers' attractiveness scores were lower. A racer's attractiveness thus depends on the competitors' attractiveness in a race. Therefore, we focused on the relative attractiveness in a race rather than absolute attractiveness. As shown in Table 1, for a racer's Attractiveness, we used a place ranking of the attractiveness scores of the 6 racers competing in a given race, which ranges from 1 (least attractive) to 6 (most attractive). ${ }^{12}$

\footnotetext{
11 For comparison of attractiveness scores between male and female evaluators, we illustrate scatter plots in appendix. Vertical and horizontal lines indicate male and female evaluators' mean scores for 1496 racers. This clearly shows that male evaluators scores are similar to those of female evaluators. Therefore, attractiveness scores are less likely to depend on genders.

12 Racers' absolute attractiveness does not change and is captured by racers' dummies. We conducted OLS estimations where Attractiveness (relative attractiveness) is the dependent variable and racers' dummies are independent variables. Its $R^{2}$ is about 0.70 , which is very high. This means that relative attractiveness is strongly correlated with absolute attractiveness, such that the higher the attractiveness score, the higher the place of the attractiveness score among the six racers.
} 


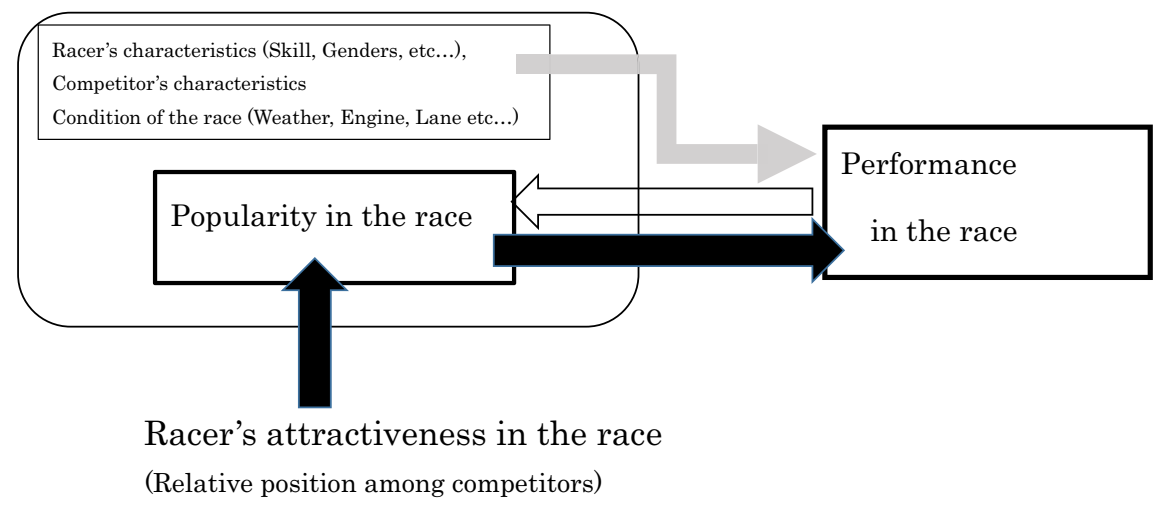

Fig. 2 Analytical framework

\section{Analytical framework}

\subsection{Hypothesis}

Figure 2 illustrates the analytical framework of this study, including the three key components: racers' attractiveness, racers' popularity in the race, and racers' performance in the race. The study aimed to examine how racers' attractiveness influences race performance by considering the channel through which attractiveness affects racers' popularity in races. The inverse of betting odds was used to measure a racer's popularity relative to that of the five competitors in a race. Individuals bet money on a racer because they expect the racer to win the race and then earn benefits. ${ }^{13}$ Apart from the expectation of winning, Forrest and Simmons (2008) suggested that bettors tend to have a wager on their home team. Bettors also tend to lay a wager on attractive racers. We can explain the reason why bettors prefer the relatively better looking racers despite having the same ability. One possibility is that bettors believe that there may be a correlation between absolute good looks and unobservable productivity. Bettors may be more likely to vote for a racer who is relatively good looking because they know the correlation. As long as bettors have an incentive to win the bet, they will want to put it on the racer who has the best chance of winning. Another possibility is that consumers tend to prefer certain attributes, such as consumer discrimination. Bettors may derive utility from the very act of rooting for a beautiful racer.

As shown in Fig. 2, we tested whether the racers' relative attractiveness in a race determines their popularity. Furthermore, we assumed that attractiveness is not correlated with race performance. Some researchers might not agree with our assumption because it is inconsistent with the effort-enhancing effect of beauty

\footnotetext{
13 We used rank of popularity among six racers in a race because data on betting odds were not available.
} 
(Ahn and Lee 2014). However, in the setting of this study, a racer's inherent attractiveness does not change and so does not depend on competitors. After controlling for this fixed effect of attractiveness, as explained in the previous section, we focused on attractiveness relative to competitors in a race. As such, a racer's attractiveness varied in each race. The effort-enhancing effect of beauty is thought to be derived from a person's inherent attractiveness, which is controlled by a fixed effect in this study. Moreover, differing from major sports like football, baseball, and tennis, Japan boat racing is a minor sport, and thus, racers' side job earnings are very small. Nonetheless, 'super stars' in this field may be able to earn a large amount of money. To remove the effort-enhancing channel and super star effects, we conducted estimations by limiting the sample: we excluded A1 racers.

Popularity and performance may also have reverse causality. A racer's popularity in a race is determined before the race, whereas the racer's performance is the outcome of the race. Inevitably, there is a time lag between popularity and performance. Popularity in races is reflected in the inverted value of betting odds. Popularity depends on a racer's performance in past races, which leads to bettors' expectations. Using a rich dataset, we controlled for various factors, such as innate racers' talent, racers' absolute level of skill, and relative skill among competitors in the fixed-effects model, along with other information on race conditions. Specific unofficial information may relate to racers' popularity and performance. For instance, bettors obtain race information and prediction through boat racing magazines. Consequently, endogeneity bias occurs. To control for the bias, IV estimation should be used.

In the estimation model, we controlled for endogeneity bias and various factors related to racers' ability and performance. Hence, apart from the bettors' expectation on winning probability, we analysed how popularity influences racers' performance. Racers knowing their own betting ratio, thereby their popularity relative to competitors, may affect motivation. For instance, racers might have an incentive to meet fans' expectations, which could improve their performance. Racers might also unconsciously feel pressure or tensed, which could lower their performance.

The effect of popularity on racers' performance might not be different among racers if such popularity reflects only the subjective assessment of bettors on racers winning, which is based on bettors' information. That is, the effect of popularity might be different according to racers' character: a racer's reaction to popularity depends on his/her character. For instance, under the highly competitive pressure in professional sports, women tend to display less aggressive behaviour (Booth and Yamamura 2018) and make mistakes (Paserman 2010). If so, women are less able to improve their performance when they are more popular in a race. Therefore, we opted to split the data of person-race observations into men and women races to compare the estimation results between men and women racers.

Based on the argument above, we propose three hypotheses as follows:

Hypothesis 1: racers' attractiveness makes them popular regardless of their ability.

Hypothesis 2: racers have an incentive to improve their performance to meet the expectation of bettors when they are more popular in races. 
Hypothesis 3: the effect of popularity on male racers' performance is larger than that on female racers' performance.

If these hypotheses hold, there may be causality expressed in the black solid arrows in Fig. 1. The effect of attractiveness investigated in this study may be called the expectation-enhancing effect. This effect is distinct from the productivity-enhancing effect of attractiveness provided by Biddle and Hamermesh (1998) because there is no need for social and communication skills to improve racers' performance. Moreover, prize winnings for racers do not depend on the betting odds; only the benefit for bettors greatly depends on the odds. Hence, this study does not examine the effort-enhancing effect of attractiveness (Ahn and Lee 2014).

Racers' confidence derived from their attractiveness possibly influences their performance (Mobius and Rosenblat 2006). However, confidence is thought to be formed through various experiences in the long term and can be accumulated stock. Therefore, we assumed that confidence does not change across races. Although confidence relates to the absolute value of attractiveness, which is captured by fixed effects in this study, we focused on the ranking of racers' attractiveness in each race, which, we believe, is independent of confidence.

\subsection{Empirical model}

For testing the hypotheses, we used the following model, and estimated it with the IV method taking Attractiveness as the excluded IV.

$$
Y_{i k}=\alpha_{1} \text { Popular }_{i k}+X_{i t} \prime B+Y_{i t} \prime C+e_{i}+m_{k}+u_{i k}
$$

Before proceeding to IV estimation, let us begin with the explanation of the estimation of Eq. (1) regarding Popularity as an exogenous variable. It is necessary to control for racers' individual time-invariant characteristics, such as inherent ability and physical attractiveness. To this end, we employed the fixed-effects model in the baseline model. The dependent variable $Y$ denotes performance of individual $i$ on race $k$. Place in race and race time are both relevant information for capturing a racer's performance. Place matters more to the racers and bettors because it translates directly into winnings. Racers want to travel faster than competitors to finish at a higher place. Hence, although there are two different measure proxies, the principal performance covariate is place in races, ranging from 1 (sixth place; top) to 6 (first place; bottom) in races in which six racers compete. In the estimation, the inverted $\log$ of race time, i.e. $1 / \log$ (race time), is used to imply that larger values show a higher performance. ${ }^{14}$ Popularity is the order of betting odds among six racers: 1 (least popular; largest odds) to 6 (most popular; smallest odds). ${ }^{15} \alpha_{l}$, the coefficient

\footnotetext{
${ }^{14}$ The time in second is used for race time. As is exhibited in Table 1, Its mean value is around 112. Its inverted value becomes very small, which is difficult to interpret. Hence, inverted log of race time is used.

${ }^{15}$ We could not obtain betting odds data. Hence, betting odds could not be included as independent variables.
} 
of Popularity, is expected to have the positive sign because more popular racers are more likely to rank higher (better performance).

As found by Yamane and Hayashi (2015), the performance of adjacent competitors positively influences swimmers' performances. Therefore, it is crucial to control for order in skill, which is regarded as a racer's relative skill to win among competitors in a race. The row vector $\boldsymbol{X}_{i t}$ captures their controls, such as relative racer's skill and weight, relative motor unit performance, and dummy for lane. Unobservable individual time-invariant characteristics $e_{i}$ are controlled for through fixed effects estimation. The outcome of boat racers is greatly influenced by natural conditions because the races are on water and in an open air environment. $m_{k}$ refers to race conditions, such as wave, wind speed, and weather. To compare results between men and women, we opted to split the data of person-race observations into men and women races. ${ }^{16}$

In the IV estimation of Eq. (1), we conducted closer examinations of the fixedeffects IV model for exploring causality. As explained in Sect. 3 and illustrated in Fig. 1, the endogeneity bias of Popularity $i k$ was controlled by the excluded IV Attractiveness. From Hypothesis 1 proposed in Sect. 3, in the first stage of the model, the coefficient of Attractiveness is expected to have the positive sign because more attractive racers are more popular. For testing Hypotheses 2 and 3, in the second stage, the coefficient of Popularity suggests whether the effect of popularity relative to that of competitors' influences a racer's performance. From Hypothesis 2, the coefficient of popularity is expected to have the positive sign. Hypothesis 3 leads to the prediction that popularity's absolute value for male racers is larger than that for female racers.

\section{Estimation results}

\subsection{Baseline fixed-effects model}

Table 2 reports the results of the fixed-effects estimation of the baseline model where the dependent variable is place in race (from first to sixth). Various control variables were included in the estimations, although their results are not reported in the table. Results based on the men racers sample are in columns (1) and (2), whereas those on women are in columns (3) and (4).

Compared with lower-grade racers, A1 racers are far more well known and popular, and have greater opportunity to earn additional earnings, for instance, by appearing in TV commercials. Therefore, the effort-enhancing effect may occur (Ahn and Lee 2014). A kind of 'super star effect' is considered to be in the error terms and correlated with both racers' performance and popularity, causing endogeneity bias. To remove the effort-enhancing and super star effects, we limited the sample where we excluded A1 racers. Columns (1) and (3) in Table 2 are on the sample of A1, A2,

\footnotetext{
16 There are races where both men and women racers compete together. We did not include these races into the sample.
} 
Table 2 Baseline estimation (fixed effects): 'Place in race' as dependent variable. Estimation results of Eq. (1)

\begin{tabular}{|c|c|c|c|c|}
\hline & \multicolumn{2}{|l|}{ Men } & \multicolumn{2}{|l|}{ Women } \\
\hline & All grades (1) & Excluding A1 (2) & All grades (3) & Excluding A1 (4) \\
\hline Popular & $0.29 * * *(0.003)$ & $0.28 * * *(0.003)$ & $0.32 * * *(0.011)$ & $\begin{array}{l}0.30 * * * \\
(0.011)\end{array}$ \\
\hline Order of racers' grades & $0.09 * * *(0.003)$ & $0.11 * * *(0.003)$ & $0.09 * * *(0.010)$ & $0.11 * * *(0.011)$ \\
\hline $\begin{array}{l}\text { Order of racers' win- } \\
\text { ning rates }\end{array}$ & $0.07 * * *(0.003)$ & $0.06 * * *(0.003)$ & $0.07 * * *(0.009)$ & $0.06 * * *(0.010)$ \\
\hline $\begin{array}{l}\text { Order of motor units' } \\
\text { performance }\end{array}$ & $0.03 * * *(0.002)$ & $0.03 * * *(0.002)$ & $0.04 * * *(0.006)$ & $0.04 * * *(0.006)$ \\
\hline Order of racer's weight & $-0.02 * * *(0.002)$ & $-0.01 * * *(0.003)$ & $-0.05 * * *(0.009)$ & $-0.04 * * *(0.010)$ \\
\hline Motor unit performance & $0.002 * * *(0.0002)$ & $0.002 * * *(0.003)$ & $0.001(0.001)$ & $0.002 * *(0.001)$ \\
\hline Racers' weight & $-0.10^{* * *}(0.004)$ & $-0.10 * * *(0.004)$ & $-0.08 * * *(0.011)$ & $-0.09 * * *(0.011)$ \\
\hline Lane_1 & Reference group & & & \\
\hline Lane_2 & $-0.49 * * *(0.011)$ & $-0.41 * * *(0.014)$ & $-0.23 * * *(0.035)$ & $-0.21 * * *(0.045)$ \\
\hline Lane_3 & $-0.58 * * *(0.011)$ & $-0.50 * * *(0.014)$ & $-0.36 * * *(0.033)$ & $-0.33 * * *(0.042)$ \\
\hline Lane_4 & $-0.67 * * *(0.011)$ & $-0.59 * * *(0.015)$ & $-0.48 * * *(0.037)$ & $-0.45^{* * *}(0.047)$ \\
\hline Lane_5 & $-0.72 * * *(0.012)$ & $-0.66^{* * *}(0.016)$ & $-0.55 * * *(0.038)$ & $-0.54 * * *(0.046)$ \\
\hline Lane_6 & $-0.75 * * *(0.013)$ & $-0.72 * * *(0.017)$ & $-0.61 * * *(0.043)$ & $-0.61 * * *(0.053)$ \\
\hline Wave & $-0.01 * * *(0.003)$ & $-0.01 * * *(0.003)$ & $-0.01(0.009)$ & $-0.01(0.010)$ \\
\hline Wind speed & $0.005 *(0.002)$ & $0.005 *(0.003)$ & $0.007(0.008)$ & $0.01(0.008)$ \\
\hline Fine weather & $0.003(0.005)$ & $-0.002(0.006)$ & $-0.001(0.017)$ & $-0.012(0.020)$ \\
\hline Rain & $-0.005(0.008)$ & $-0.003(0.009)$ & $-0.007(0.027)$ & $-0.005(0.030)$ \\
\hline Within R-square & 0.20 & 0.18 & 0.20 & 0.19 \\
\hline Groups & 1,294 & 1,001 & 182 & 158 \\
\hline Observations & 429,590 & 304,230 & 35,759 & 28,820 \\
\hline
\end{tabular}

Notes: $* * *$ and $* *$ denote statistical significance at the $1 \%$ and $5 \%$, levels, respectively. Numbers in parentheses are robust standard errors. For convenience of interpretation, values of the coefficient for "number of participated races" are multiplied by 1000. Control variables include dummies for four racers' grades, five race grades, 24 stadia, year, month, and day. These control variables are included in all estimations, but not all results are reported

B1, and B2 racers, whereas columns (2) and (4) are on sample of A2, B1, and B2 racers.

As for Table 2, Popularity shows the positive sign and statistical significance at the $1 \%$ level in all columns. This outcome is in line with our inference. The absolute value of coefficients was almost around 0.30 in all estimations. This suggested that a rise in popularity by rank among the six racers resulted in the rise of place in a race by 0.30 . For example, a racer's place in a race rises approximately by one place if the popularity rank improves from 6th to 3rd. Among the independent variables, Order of racers' grades and Order of racers' winning rates captured a relative racer's skill using the racer's and competitors' race performance records prior to a race. A larger value of these variables indicated higher skills. In addition, Order of motor units' performance captures relative quality of motor assigned to the racer. 
Table 3 Baseline estimation (fixed effects) with 'inverted log of recorded race times in races' as dependent variable. Estimation results of Eq. (1)

\begin{tabular}{|c|c|c|c|c|}
\hline & \multicolumn{2}{|l|}{ Men } & \multicolumn{2}{|l|}{ Women } \\
\hline & All grades (1) & Excluding A1 (2) & All grades (3) & Excluding A1 (4) \\
\hline Popularity & $0.24 * * *(0.005)$ & $0.24 * * *(0.006)$ & $0.28 * * *(0.016)$ & $0.27 * * *(0.019)$ \\
\hline Order of racers' grades & $0.01 * *(0.005)$ & $0.01 *(0.006)$ & $-0.006(0.019)$ & $0.01(0.20)$ \\
\hline $\begin{array}{l}\text { Order of racers' winning } \\
\text { rates }\end{array}$ & $-0.02 * * *(0.004)$ & $-0.03 * * *(0.006)$ & $-0.04 * *(0.015)$ & $-0.05 * * *(0.018)$ \\
\hline $\begin{array}{l}\text { Order of motor units' } \\
\text { performance }\end{array}$ & $0.03 * * *(0.003)$ & $0.02 * * *(0.003)$ & $0.02 * *(0.009)$ & $0.01(0.010)$ \\
\hline Order of racers' weight & $0.009 *(0.005)$ & $0.001(0.001)$ & $0.001(0.018)$ & $0.008(0.021)$ \\
\hline Motor unit performance & $0.007 * * *(0.0004)$ & $0.01 * * *(0.006)$ & $0.009 * * *(0.001)$ & $0.01 * * *(0.001)$ \\
\hline Weight & $-0.15^{* * *}(0.007)$ & $-0.15 * * *(0.008)$ & $-0.10 * * *(0.021)$ & $-0.11 * * *(0.023)$ \\
\hline Lane_1 & Reference group & & & \\
\hline Lane_2 & $-0.60 * * *(0.015)$ & $-0.52 * * *(0.019)$ & $-0.32 * * *(0.044)$ & $-0.27 * * *(0.052)$ \\
\hline Lane_3 & $-0.70 * * *(0.015)$ & $-0.61 * * *(0.020)$ & $-0.50 * * *(0.048)$ & $-0.42 * * *(0.060)$ \\
\hline Lane_4 & $-0.81 * * *(0.017)$ & $-0.70 * * *(0.021)$ & $-0.62 * * *(0.050)$ & $-0.56 * * *(0.062)$ \\
\hline Lane_5 & $-0.90 * * *(0.019)$ & $-0.80 * * *(0.024)$ & $-0.76^{* * *}(0.062)$ & $-0.68 * * *(0.071)$ \\
\hline Lane_6 & $-1.00 * * *(0.021)$ & $-0.91 * * *(0.027)$ & $-0.96 * * *(0.070)$ & $-0.87 * * *(0.080)$ \\
\hline Wave & $-0.15^{* * *}(0.005)$ & $-0.15 * * *(0.005)$ & $-0.19 * * *(0.017)$ & $-0.18 * * *(0.020)$ \\
\hline Wind speed & $-0.10^{* * *}(0.004)$ & $-0.10 * * *(0.005)$ & $-0.11 * * *(0.014)$ & $-0.10 * * *(0.016)$ \\
\hline Fine weather & $0.03 * * *(0.010)$ & $0.03 * * *(0.010)$ & $-0.02(0.030)$ & $-0.02(0.036)$ \\
\hline Rain & $-0.10 * * *(0.013)$ & $-0.11 * * *(0.016)$ & $-0.29 * * *(0.040)$ & $-0.29 * * *(0.048)$ \\
\hline Within R-square & 0.27 & 0.26 & 0.27 & 0.27 \\
\hline Groups & 1,293 & 1,000 & 182 & 158 \\
\hline Observations & 332,946 & 224,947 & 27,777 & 21,551 \\
\hline
\end{tabular}

Notes: $* * *$ and $* *$ denote statistical significance at the $1 \%$ and $5 \%$, levels, respectively. Numbers in parentheses are robust standard errors. For convenience of interpretation, values of coefficient and its standard errors are multiplied by 100. Control variables are dummies for four racers' grades, five race grades, 24 stadia, year, month, and day. These control variables are included in all estimations, but not all results are reported

The larger the value of the Order of motor units' performance, the better the quality of the motor unit. These variables showed the positive sign and were statistically significant at the $1 \%$ level. Order of racers' weight captured racers' relative physical condition. The larger the value of this variable, the heavier the racer is. Its coefficient exhibited the significant negative sign, implying that the heavier racer has a disadvantage in the race.

Motor unit performance and racers' weight vary per race, whereas a racer's inherent attractiveness and grade are fixed and captured by the fixed effects. Hence, the effects of Motor units' performance and Racers' weight could be estimated; they showed the positive and negative sign, respectively. They were almost statistically significant, consistent with their relative effects. Lane dummies (Lane_2 to Lane_6; Lane_1 is reference) showed the negative sign and statistical significance. 
This outcome is consistent with the argument that the racer in the inner lane has great advantage. Dummies for natural conditions, such as Wave, Wind speed, Fine weather, and Rain, were less likely to influence place in the race. All racers in a race are in the same natural conditions and so their relative performance (place in the race) is not influenced by them.

Table 3 presents the estimation results where the alternative racer performance variable, 'inverted log of recorded race time', is the dependent variable. Popularity showed the positive sign and statistical significance throughout. Other control variables showed similar results to those in Table 2, indicating the robustness of the estimation results. The exception was the variable of natural conditions, which reasonably showed statistical significance to the race time: the Wave, Wind-speed, and Rain dummies showed the significant negative sign, whereas the Fine weather dummy showed the significant positive one. That is, bad natural conditions deteriorate the time record, whereas good natural conditions (fine day) improve it.

\subsection{Fixed-effects IV model}

Table 4 presents the results of the fixed-effects IV model, where place in races is the dependent variable. Table 4 reports the IV estimation results of Eq. (1), including only the estimates on Popularity in the second stage Eq. (1); all the other control variables were included in the estimation. For the first-stage estimation, the results of Attractiveness (the excluded IV) and other control variables are reported.

In the first stage, it is essential to check the validity of excluded instruments, based on various tests for weak, under, and over-identification. However, inTable 4, the excluded IV is only Attractiveness, and so the model is just identified. Accordingly, we reported result of only a weak identification test. ${ }^{17}$ The null hypothesis being tested is that the estimator is weakly identified in the sense that it is subject to bias that the investigator finds unacceptably large (Baum et al. 2007, p. 489). In columns (1) and (2), the $F$-statistic is larger than 16.4, corresponding to Stock-Yogo critical values at the $10 \%$ level, and thus we reject the hypothesis of weak instruments. With the exception of column (3) and (4), the results of the tests rejected the null hypotheses that the equation is weakly identified. In alternative specifications exhibited in Table 5, instead of Attractiveness, dummies to capture racers' rank of Attractiveness among racers were used as exogenous instruments. Table 5 shows the results for weak, under-, and over-identification in male samples to indicate instrument validity. However, for female samples, the results did not lead to rejection of the null hypothesis of weak instruments. These results suggest the validity of the instruments for male but not female samples. The coefficient of Attractiveness yielded the positive

\footnotetext{
17 As Baum et al. (2007, pp. 289-290) explained, the weak-instruments problem arises when the correlations between the endogenous regressors $(\mathrm{X})$ and the excluded instruments $(\mathrm{Z})$ are not zero, but small. The weak-instruments problem can occur even when the correlations between $\mathrm{X}$ and $\mathrm{Z}$ are significant at conventional levels (5\% or 1\%) and the researcher is using a large sample. Therefore, rejecting the null of under-identification and conventional significance levels is not enough, and the weak identification test is indicated.
} 


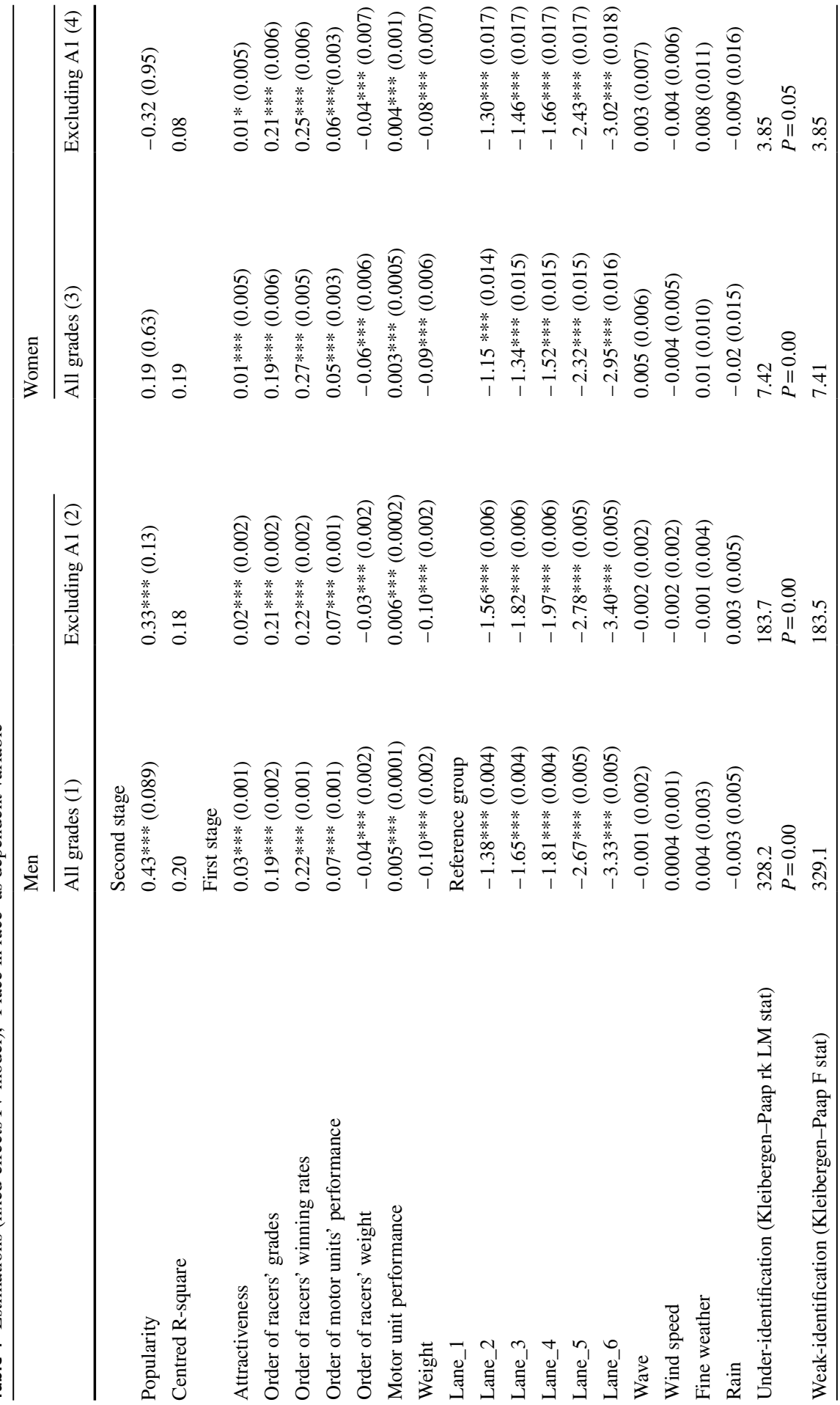




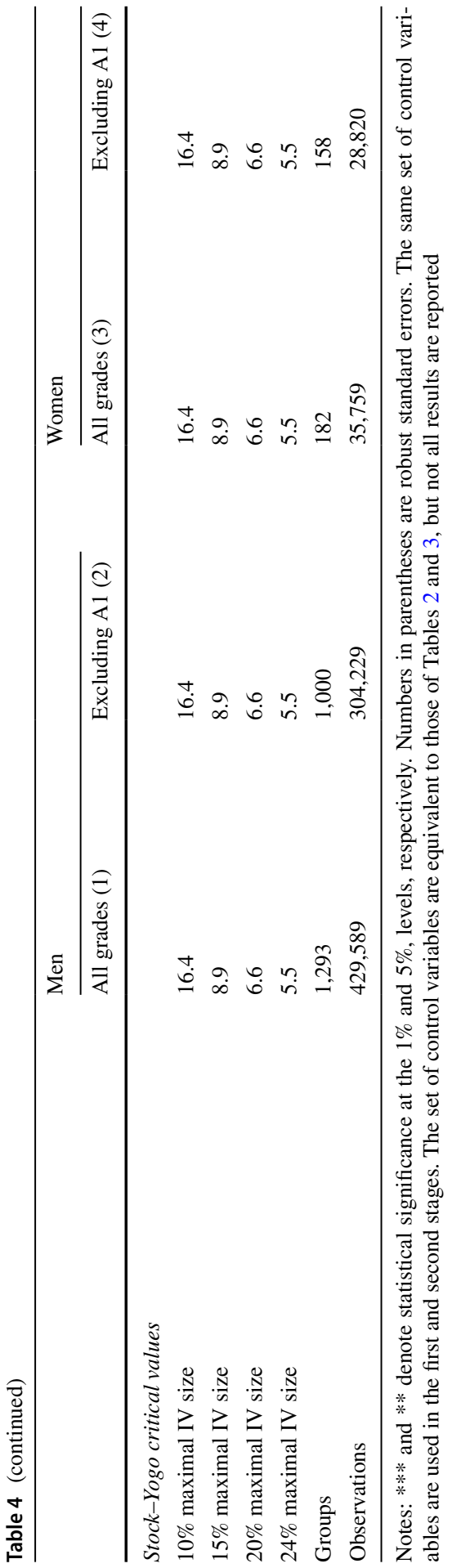




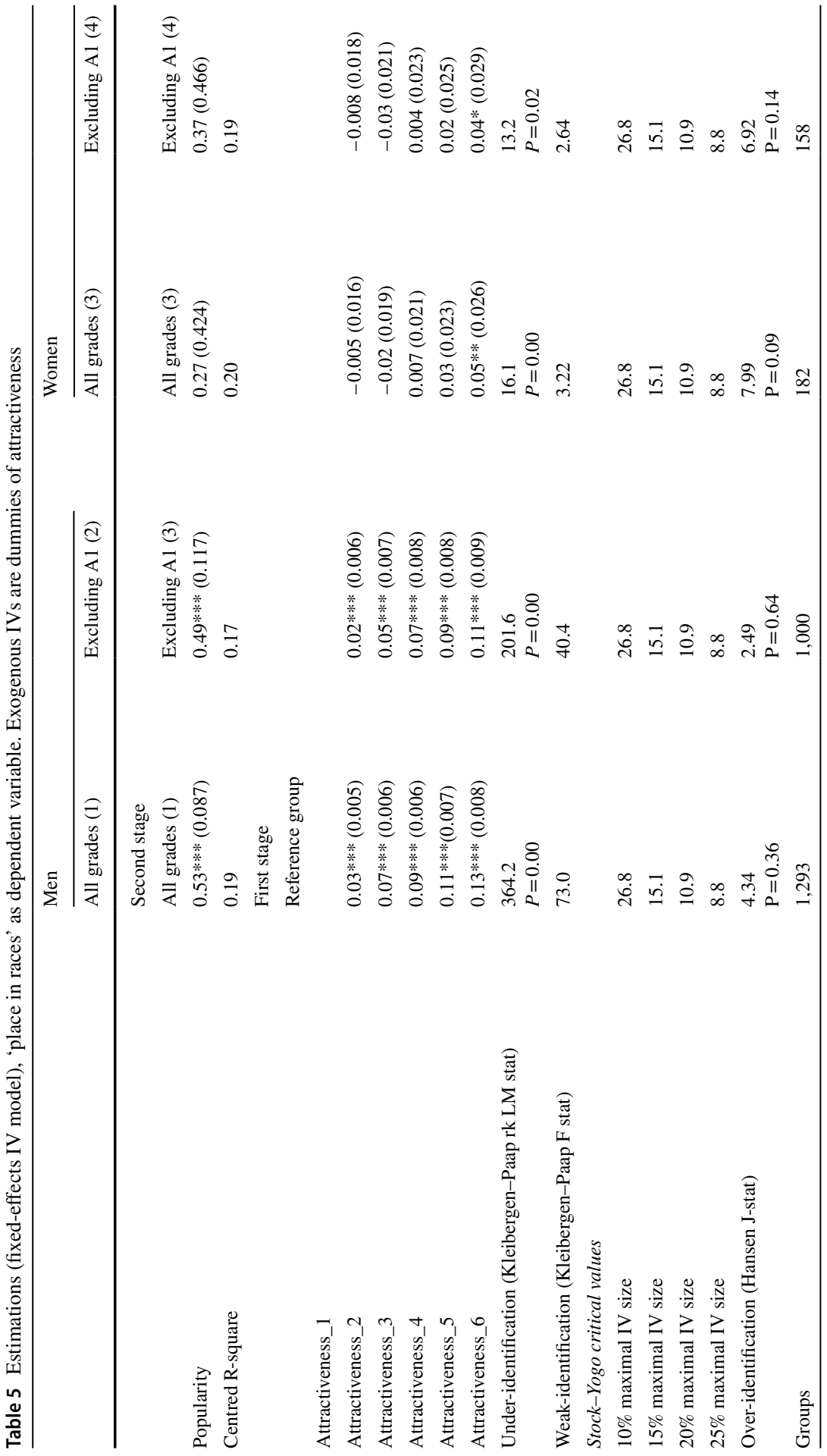




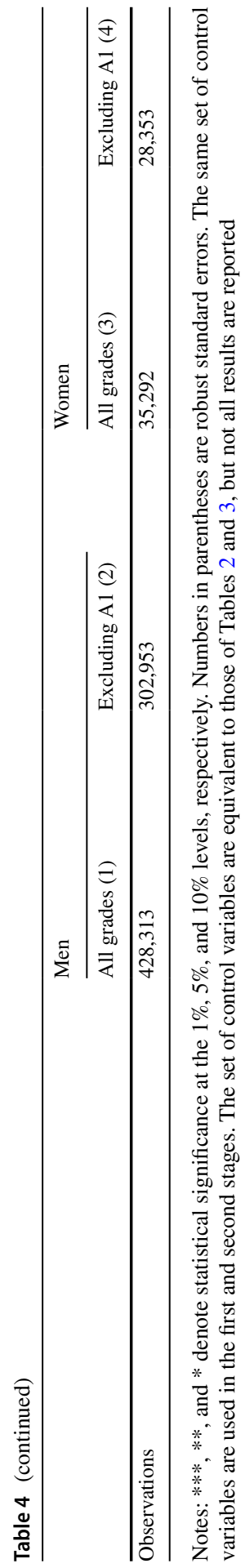


sign and statistical significance in all columns. In the male sample, dummies for attractiveness significantly showed the positive sign and the coefficient's values were larger in the higher-ranked racers; in the female sample, the dummies did not show robust results. Nonetheless, these observations support Hypothesis 1. In our interpretation, attractiveness from appearance differed between males and females. When evaluating attractiveness, people emphasized tough-looking faces for males but sweet and pretty faces for females. We should consider the role of attractiveness in this situation. In a situation of competition such as the boat race, racers compete to win. In this setting, a racer's tough-looking face plays a greater role in increasing fans' expectation of the racer winning if other demographic characteristics are equal. Put differently, a sweet and pretty face is unlikely to increase expectations.

In the second stage, the sign of Popularity was positive and statistically significant at the $1 \%$ level in columns 1 and 2 for the men's sample. Popularity showed statistical insignificance in column 3 and for the women's sample. In our interpretation, even after controlling for the fixed effects and endogeneity of Popularity, men racers improved their performance to meet the expectations of bettors. Meanwhile, the expectation does not lead women to improve their performance under the assumption that women cannot exhibit their usual performance under high pressure. This result is in line with the findings of Paserman (2010). That is, for women, positive Popularity effect seems to be neutralized by the detrimental effect of social pressure for women racers. Thus, Hypotheses 2 and 3 were supported.

From the sample of all men racers, the absolute value of the coefficient ofРориlarity (0.43) was 1.5 times larger than 0.29 in Table 2, indicating reverse causality from Performance (result of the race) to Popularity (betting odds before the race). It is reasonable to think that a higher Performance causes higher Popularity. Therefore, the endogeneity is considered to cause the over-estimation bias in the fixed-effects model; controlling the bias could reduce the value of the coefficient of Popularity. As shown in Table 4, the fixed effect IV model showed larger coefficient's values compared with the baseline model of Table 2. An explanation is that some other mechanism might be at work between these two variables. ${ }^{18}$ We believe the following effect is important: individuals have the motivation to bet on a racer whose probability of winning is expected to be low because bettors aim at the jackpot (Griffith 1949). Hence, those whose performances were relatively low might be subjects of larger wagers.

As for the specification where the inverted log of race time is the dependent variable,Table 6 shows the results of key variables. All the control variables are equivalent to those in, Table 4. Overall, the results are similar to those in Table 4. Ariely et al. (2009) provided evidence on the same by conducting experiments that high monetary rewards can decrease performance. In professional sports, enthusiastic supporters' expectation for players' performance generates pressure. Dohmen (2006), in studying professional football players, reported that players' performance

\footnotetext{
18 There may be measurement error because order of the betting odds as a proxy for popularity. This inevitably leads to attenuation bias.
} 
Table 6 Estimations (fixed-effects IV model), 'inverted log of recorded race times in races' as dependent variable

\begin{tabular}{|c|c|c|c|c|}
\hline & \multicolumn{2}{|l|}{ Men } & \multicolumn{2}{|l|}{ Women } \\
\hline & All grades (1) & Excluding A1 (2) & All grades (3) & Excluding A1 (4) \\
\hline & Second stage & & & \\
\hline Popularity & $0.32 * *(0.144)$ & $0.35 *(0.199)$ & $-1.16(1.46)$ & $-0.99(1.69)$ \\
\hline \multirow[t]{2}{*}{ Centred R-square } & 0.64 & 0.65 & 0.62 & 0.63 \\
\hline & First stage & & & \\
\hline Attractiveness & $0.03 * * *(0.002)$ & $0.02 * * *(0.002)$ & $0.01 * *(0.005)$ & $0.01 *(0.006)$ \\
\hline $\begin{array}{l}\text { Under-identification } \\
\text { (Kleibergen-Paap rk LM stat) }\end{array}$ & $\begin{array}{l}275.6 \\
P=0.00\end{array}$ & $\begin{array}{l}153.9 \\
P=0.00\end{array}$ & $\begin{array}{l}4.03 \\
P=0.04\end{array}$ & $\begin{array}{l}2.88 \\
P=0.09\end{array}$ \\
\hline $\begin{array}{l}\text { Weak-identification (Kleiber- } \\
\text { gen-Paap F stat) }\end{array}$ & 276.3 & 154.2 & 4.03 & 2.87 \\
\hline \multicolumn{5}{|l|}{ Stock-Yogo critical values } \\
\hline $10 \%$ maximal IV size & 16.3 & 16.3 & 16.3 & 16.3 \\
\hline $15 \%$ maximal IV size & 8.9 & 8.9 & 8.9 & 8.9 \\
\hline $20 \%$ maximal IV size & 6.6 & 6.6 & 6.6 & 6.6 \\
\hline $25 \%$ maximal IV size & 5.5 & 5.5 & 5.5 & 5.5 \\
\hline Groups & 1,293 & 1,000 & 182 & 158 \\
\hline Observations & 332,946 & 224,947 & 27,777 & 21,551 \\
\hline
\end{tabular}

Notes: $* * *, * *$, and $*$ denote statistical significance at the $1 \%, 5 \%$, and $10 \%$ levels, respectively. Numbers in parentheses are robust standard errors. For convenience of interpretation, values of the coefficient and its standard errors for popularity are multiplied by 100 . The same set of control variables are used in the first and second stages. The set of control variables are equivalent to those of Tables 2 and 3 , but not all results are reported

is negatively affected by the presence of a supportive audience. ${ }^{19}$ Contrary to the negative effect of supporters, pressure from the support of an audience and fans has a greater influence on the referee's decision-making, influencing game outcomes. In sports games, social pressure from supporters for the home team leads referees to make decisions that favour the home team (Dohmen and Sauermann 2016; Garicano et al. 2005), whereas games with no audience do not show the referee's 'favourism' (Pettersson-Lidbom and Priks 2010).

In amateur sports where there are no monetary rewards for winners, some players might have greater incentive to win, if cheered by a greater number of people. For instance, individual athletes 'may be more motivated to achieve Olympic fame when the events are conducted in front of friends and family' (Bernard and Busse 2004, p. 414). People support players because of shared identities, such as nationality or locality. The factor causing spectators to support players is not related to the probability of winning and to monetary gains from players' winning. The same holds for our analysis: racers' physical attractiveness is not related to racers' ability or probability of winning. However, attractiveness causes spectators to support and expect

\footnotetext{
${ }^{19}$ Attendance in games does not influence the professional football players' performance (Braga and Guillen 2012).
} 
much from the players even if the players' ability and probability of winning are controlled. Bettors have a wager on attractive racers, all other things being equal. In turn, racers have an incentive to improve their performance, although the monetary rewards for racers do not depend on betting odds. In other words, the expectationenhancing effects of physical attractiveness improve the men racers' performance. ${ }^{20}$ However, this effect seems to be neutralized by the detrimental effect of social pressure for women racers. As such, physical attractiveness indirectly gives men racers a great incentive to improve their performance, resulting in long-term skill accumulation, whereas in women racers, physical attractiveness does not contribute to performance and skill accumulation.

\section{Conclusion}

Monetary and non-monetary incentives cause individuals to change their behaviour. In the novel setting of boat racing where men and women compete in the same conditions, the unique data allowed us to scrutinize how non-monetary incentives lead to different outcomes between men and women. Our main research interest was to analyse how racers' physical attractiveness gives bettors a non-monetary incentive to wager and how racers react to the expectation from bettors when the rewards of winning do not depend on their odds ratio (expectation). The major findings through the fixed-effects IV estimations were as follows. (1) Bettors were likely to wager on racers who were more attractive than their competitors. (2) Men racers displayed better performance as a larger number of bettors wager on them. However, this tendency was not observed for women racers. Thus, an implication is that men have a greater incentive to win even if their rewards are the same, as a larger number of bettors would suffer loss and be disappointed unless the racers win.

Men racers have a motivation to avoid the bettors' loss and disappointment. In other words, men racers attempt to satisfy the bettors who bet on them, which in turn increase racers' own utility. Thus, fans' and supporters' utility in included in men racers' utility. This mechanism generates the expectation-enhancing effects of physical attractiveness. Meanwhile, apart from this effect, women racers tend to feel larger social pressure, which deters them from improving their performance. Males are more likely than females to show their real ability in more competitive environments (Gneezy et al. 2003). We can interpret this in line with our findings as

\footnotetext{
${ }^{20}$ These expectation-enhancing effects have also been observed for full-time professors of universities in Japan. At a top-ranking university in Japan such as the University of Tokyo, students' evaluations and the popularity of full-time professors' lectures do not influence the professors' income. Hence, full-time professors do not have an incentive to improve their lectures. However, some full-time professors of economics have made great efforts to improve their lectures, resulting in an increase of popularity for their class (Ichimura et al., 2020). During the COVID-19 pandemic in 2020, in some classes at the University of Tokyo, over a 1000 students attended remote lectures disseminated through the Internet by highly qualified lectures (Maeda, 2020). This phenomenon can be partly explained by expectation-enhancing effects.
} 
showing that the expectations of others give males a greater incentive to demonstrate their maximum ability.

Finally, the remaining issues need to be addressed. That the effect of popularity on female racer's performance was "not significant" did not necessarily mean that the effect is weak for female racers. Hence, to be precise, the gender gap of the expectation-enhancing effects was only a possibility that was not supported by the evidence. To provide evidence of a gender gap, it is necessary to statistically test the null hypothesis that the coefficients of the popularity measures are equal. However, there are difficulties in testing the hypothesis. Some results using the women's sample did not show the validity of IV; therefore, results of the fixed-effects IV may not be as reliable as those using the men's sample. Unbiased results can be obtained by using an appropriate experimental method for dealing with endogeneity bias. Furthermore, it would be worthwhile comparing the size of the fans' expectation effect in the present study with that of other studies; however, limitations in our study prevented our doing so. We hope that future research will explore these issues further.

Acknowledgement This study was supported by the Joint Usage/Research Center at ISER, Osaka University.

\section{Appendix}

See appendix Fig. 3.

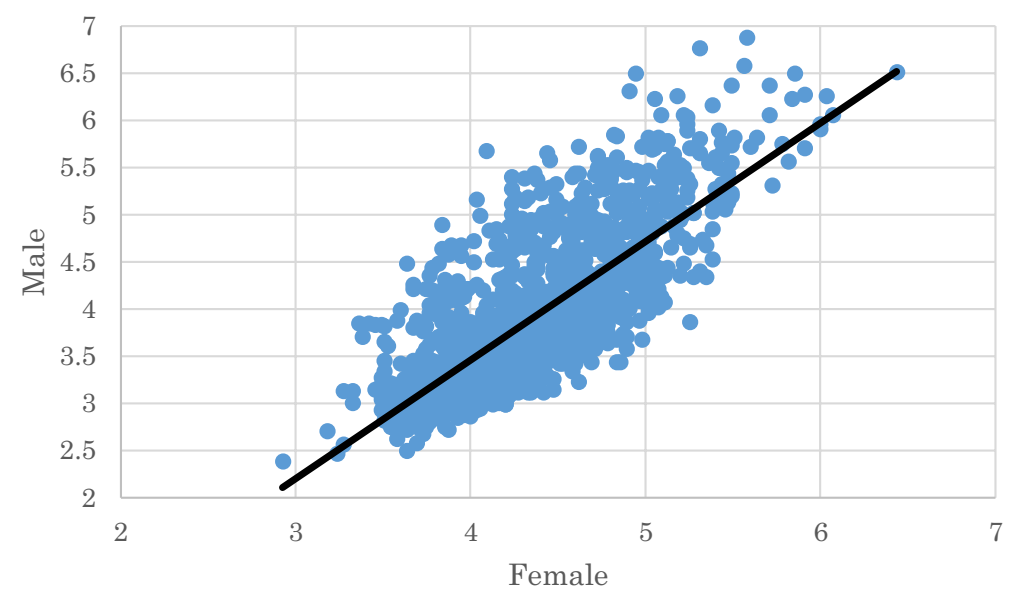

Fig. 3 Relation between male evaluators' attractiveness scores and those of female evaluators 


\section{References}

Ahn, S. C., \& Lee, Y. H. (2014). Beauty and productivity: the case of the ladies professional golf association. Contemporary Economic Policy, 32(1), 155-168.

Andreoni, J., \& Petrie, R. (2008). Beauty, gender and stereotypes: Evidence from laboratory experiments. Journal of Economic Psychology, 29(1), 73-93.

Ariely, D., Gneezy, U., \& Loewenstein, G. (2009). Large stakes and big mistakes. Review of Economic Studies, 76, 451-469.

Baum, C., Schaffer, M., \& Stillman, S. (2007). Enhanced routines for instrumental variables/generalized method of moments estimation and testing. Stata Journal, 7(4), 465-506.

Berggren, N., Jordahl, H., \& Poutvaara, P. (2010). The looks of a winner: Beauty and electoral success. Journal of Public Economics, 94(1-2), 8-15.

Berggren, Niclas, Jordahl, Henrik, \& Poutvaara, Panu. (2017). The right look: Conservative politicians look better and voters reward it. Journal of Public Economics, 146(C), 79-86.

Bernard, A. B., \& Busse, M. R. (2004). Who wins the Olympic games: economic resources and medal totals. Review of Economics and Statistics, 86(1), 413-417.

Berri, D. J., Simmons, R., \& Gilder, V. (2011). What does it mean to find the face of the franchise? Physical attractiveness and the evaluation of athletic performance. Economics Letters, 111(3), 200-202.

Biddle, J. E., \& Hamermesh, D. S. (1998). Beauty, productivity, and discrimination: lawyers' looks and lucre. Journal of Labor Economics, 16(1), 172-201.

Booth, A. (2009). Gender and competition. Labour Economics, 16, 599-606.

Booth, A., Sosa, L. C., \& Nolen, P. (2014). Gender differences in risk aversion: Do single-sex environments affect their development? Journal of Economic Behavior \& Organization, 99(2014), $126-154$.

Booth, A., \& Yamamura, E. (2018). "Performance in Mixed-sex and Single-sex Tournaments: What We Can Learn from Speedboat Races in Japan." Forthcoming in Review of Economics \& Statistics.

Braga, B., \& Guillen, D. (2012). Working under Pressure: Evidence from the Impacts of Soccer Fans on Players' Performance. Economics Letters, 114(2), 212-215.

Cárdenas, J. C., Dreber, A., von Essen, E., \& Ranehill, E. (2012). Gender differences in competitiveness and risk taking: comparing children in Colombia and Sweden. Journal of Economic Behavior and Organization, 83, 11-23.

Dohmen, T., \& Sauermann, J. (2016). Referee Bias. Journal of Economic Surveys, 30(4), 679-695.

Doorley, Karina, \& Sierminska, Eva. (2015). Myth or fact? The beauty premium across the wage distribution in Germany. Economics Letters, 129(C), 29-34.

Dreber, A., von Essen, E., \& Ranehill, E. (2011). Outrunning the gender gap-boys and girls compete equally. Experimental Economics, 14(2011), 567-582.

Dreber, A., von Essen, E., \& Ranehill, E. (2014). Gender and competition in adolescence: Tasks matter. Experimental Economics, 17, 154-172.

Dreber, Anna, Gerdes, Christer, \& Gränsmark, Patrik. (2013). Beauty queens and battling knights: Risk taking and attractiveness in chess. Journal of Economic Behavior \& Organization, 90(C), 1-18.

Eckel, C. C., \& Petrie, R. (2011). Face value. American Economic Review, 101(4), 1497-1513.

Fletcher, J. M. (2009). Beauty vs. brains: Early labor market outcomes of high school graduates. Economics Letters, 105(3), 321-325.

Forrest, D., \& Simmons, R. (2008). Sentiment in the betting market on Spanish football. Applied Economics, 40, 119-126.

Garicano, L., Palacios-Huerta, I., \& Prendergast, C. (2005). Favoritism under social pressure. Review of Economics and Statistics, 87, 208-216.

Gneezy, U., Niederle, M., \& Rustichini, A. (2003). Performance in competitive environments: Gender differences. Quarterly Journal of Economics, 118, 1049-1074.

Gneezy, Uri, \& Rustichini, Aldo (2004). "Gender and Competition at a Young Age." American Economic Review, 94, Papers and Proceedings, 377-381.

Gneezy, U., Leonard, K., \& List, J. (2009). Gender differences in competition: evidence from a matrilineal and a patriarchal society. Econometrica, 77, 1637-1664.

Griffith, R. M. (1949). Odds adjustments by American horserace bettors. American Journal of Psychology, 62, 290-294.

Hamermesh, D. S., \& Biddle, J. E. (1994). Beauty and the labor market. American Economic Review, 84(5), 1174-1194. 
Hamermesh, D. S., \& Parker, A. (2005). Beauty in the classroom: instructors' pulchritude and putative pedagogical productivity. Economics of Education Review, 24(4), 369-376.

Hamermesh, Daniel S., \& Abrevaya, Jason. (2013). Beauty is the promise of happiness? European Economic Review, 64(C), 351-368.

Himura, K.-I. (2015). Yokuwakaru Boat Race no Subete (in Japanese) (Basic Knowledge about Boat Race). Tokyo: Sankei Books.

Ichimura, H., Okazaki, T., Sato, Y., \& Akihiko, M. (2020). Keizai Gaku wo Ajiwau: Todai 1, 2 nensei ni Dai-ninki no Jugyo (in Japanese) (Enjoying economics: Very popular economics classes for firstand second-year students). Tokyo: Nihon Hyoron sha.

Jenq, Christina, Pan, Jessica, \& Theseira, Walter. (2015). Beauty, weight, and skin color in charitable giving. Journal of Economic Behavior \& Organization, 119(C), 234-253.

Khachatryan, K., Dreber, A., von Essen, E., \& Ranehill, E. (2015). Gender and preferences at a young age: Evidence from Armenia. Journal of Economic Behavior and Organization, 118, 318-332.

King, A., \& Leigh, A. (2009). Beautiful Politicians. Kyklos, 62(4), 579-593.

Maeda, Hiroyuki (2020). Todai de 1, 2 nensei no 1000 nin ga juko. Keizaigaku no ninki jugyo ga hon ni natta. (in Japanese) (Over a thousand first- and second-year students attended the class: An economics class at the University of Tokyo was published in the book). Electronic version of Nihon Keizai Shimbun, May 30, 2020. https://style.nikkei.com/article/DGXKZO59743560Z20C20A5MY5000/ (Accessed on Aug 21, 2020).

Mobius, M. M., \& Rosenblat, T. S. (2006). Why beauty matters. American Economic Review, 96(1), $222-235$.

Niederle, M., \& Vesterlund, L. (2007). Do women shy away from competition? Do men compete too much? Quarterly Journal of Economics, 122, 1067-1101.

Niederle, M., \& Vesterlund, L. (2011). Gender and competition. Annual Review of Economics, 3, 601-630.

Parrett, Matt. (2015). Beauty and the feast: Examining the effect of beauty on earnings using restaurant tipping data. Journal of Economic Psychology, 49(3), 34-46.

Paserman, Daniele (2010). "Gender Differences in Performance in Competitive Environments? Evidence from Professional Tennis Players." mimeo.

Pettersson-Lidbom, P., \& Priks, M. (2010). Behavior under social pressure: Empty Italian stadiums and referee bias. Economics Letters, 108(2), 212-214.

Pfann, G. A., Biddle, J. E., Hamermesh, D. S., \& Bosman, C. M. (2000). Business success and businesses' beauty capital. Economics Letters, 67(2), 201-207.

Price, M. K. (2008). Fund-raising success and a solicitor's beauty capital: Do blondes raise more funds? Economics Letters, 100(3), 351-354.

Rosen, S. (1981). The economics of superstars. American Economic Review, 71(5), 845-858.

Yamane, S., \& Hayashi, R. (2015). Peer effects among swimmers. Scandinavian Journal of Economics, $117,1230-1255$.

Publisher's Note Springer Nature remains neutral with regard to jurisdictional claims in published maps and institutional affiliations. 